\title{
The Beam_Optics at the Extraction Region of SNS ring; Revisited
}

\author{
N. Tsoupas, M. Hemmer, Y.Y. Lee, C.-I. Pai, J. Rank, J.L. Mi, \\ D. Raparia, S. Tepikian, J.E. Tuozzolo, J. Wei, W. Zhang
}

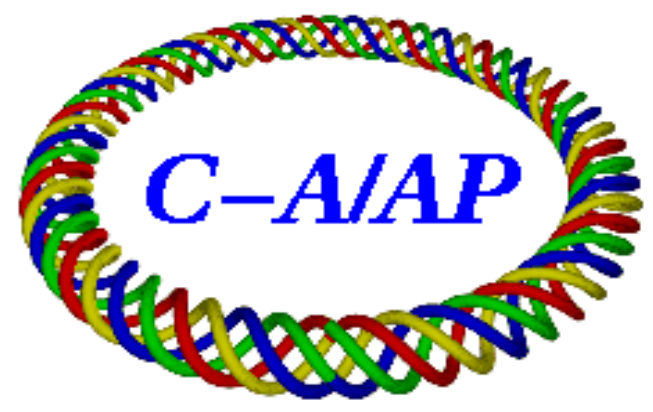

Collider-Accelerator Department Brookhaven National Laboratory Upton, NY 11973 


\title{
The Beam_Optics at the Extraction Region of SNS ring; Revisited
}

\author{
N. Tsoupas, M. Hemmer, Y. Y. Lee, C.-I. Pai, J. Rank, J. L. Mi, D. Raparia, \\ S. Tepikian, J.E.Tuozzolo, J. Wei, and, Wu Zhang
}

\section{Abstract}

The optics of the beam extraction section of SNS ring has been published in Ref. [1] where we show that by optimizing the aperture and locations of the extraction kickers, we can accomplish both, first the elimination of the beam losses for the circulating and extracted beam, and second the minimization of the required voltage applied to the coil of the extraction kickers which deflect the beam vertically to the correct location to clear the extraction septum[2]. Also a number of papers have been published $[2,3 \ldots 10]$ to discuss the extraction devices (Kickers and Extraction Septum) of the SNS ring. Mechanical constraints however at the location of the SNS extraction kickers required that all fourteen extraction kickers be moved downstream in the ring by five centimeters. In this Technical Note we present the new optics of the SNS extraction region. The results of the study show that the placements of all the extraction kickers by five centimeters downstream can generate the required beam extraction conditions by simply raising the voltage of some of the kickers by about $2 \%$ of their original settings.

\section{Introduction}

The beam extraction region[1] of the SNS ring is located in one of the four straight sections of the SNS ring. The beam extraction process, which is designed to extract the single circulating beam bunch in one turn, is based in kicking the beam downwards by $\mathrm{Y}_{\text {cod }}^{\prime} \sim 13.3 \mathrm{mrad}$ with the fourteen kickers, shown in Figure 1, (seven kickers are placed upstream of the two narrow quads NQ1 and NQ2 of the SNS ring and seven kickers are placed downstream of the narrow quads) into the Lambertson septum magnet which deflects the beam by $16.8^{\circ}$ into the RTBT line. The vertical displacement of the extracted beam at the entrance of the Extraction Septum magnet is $Y_{\text {cod }}=167.0$ $\mathrm{mm}$.

A schematic diagram of the extraction kickers and the extraction septum is shown in Figure 1. In the same figure the vertical displacement of the central orbit $\left(\mathrm{Y}_{\text {cod }}\right)$ resulted from exciting all fourteen kickers is also shown.

The location and inductance of each of the kickers was optimized to minimize the required voltage applied on each kicker to extract the beam into the septum magnet. The aperture of each kicker was also optimized to eliminate the beam losses of the circulating beam and the extracted beam.

Mechanical constraints at the location of the extraction region, required that each of the kicker assemblies is moved downstream by five centimeters from their previously chosen optimum location. In the next section of this technical note we discuss the beam optics of the extracted beam under the new placement of the extraction kickers, and we compare the required voltages applied on the kickers before and after the kicker displacement, under the condition of lossless beam extraction. 


\section{$\mathbf{Y}_{\text {cod }}$ vs Dist. during beam Extraction}

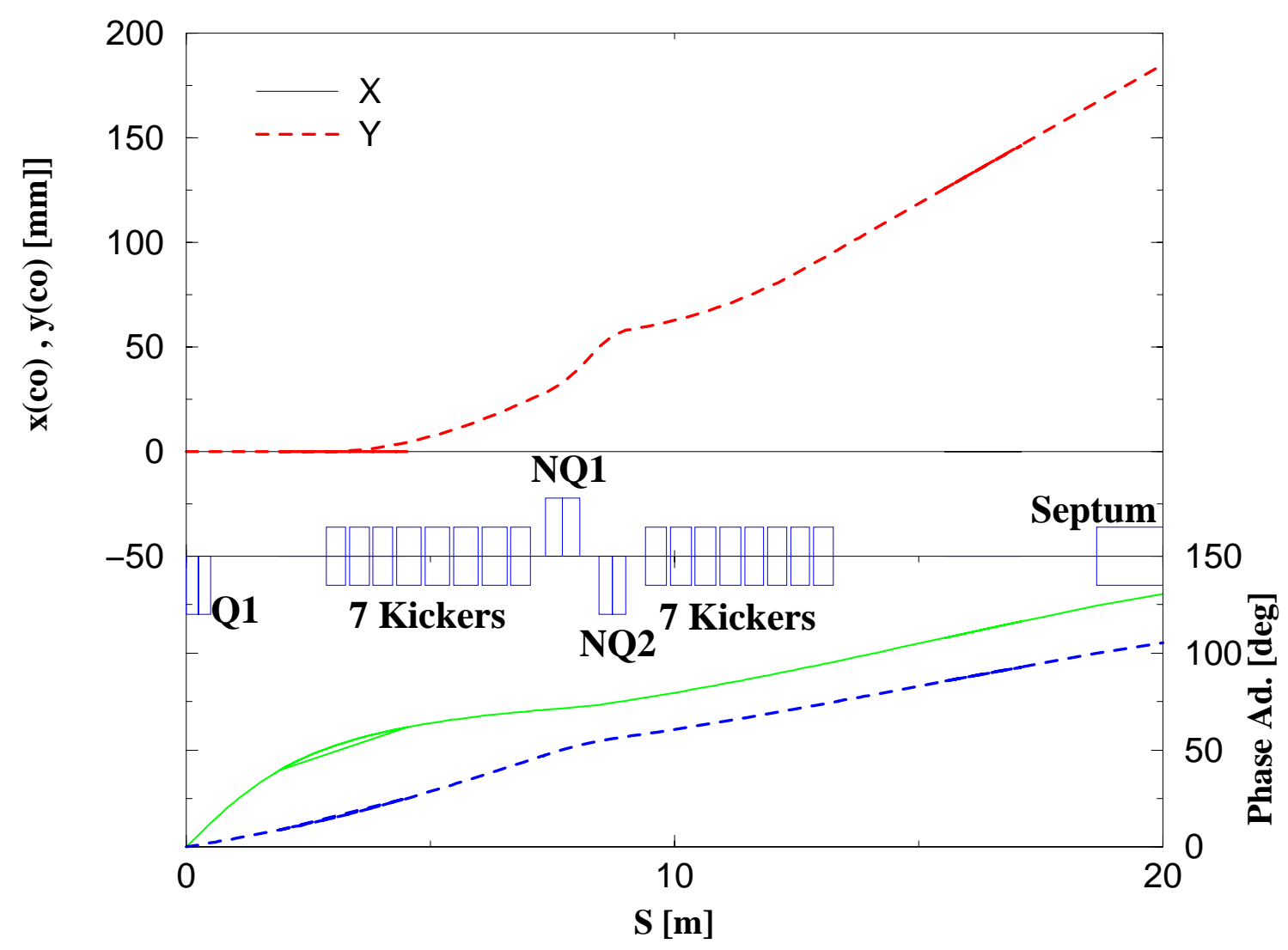

Figure 1. Schematic diagram showing the location of the extraction kickers relative to the narrow quads (NQ1,NQ2) of the SNS straight section. The last element is the septum magnet. The same figure also shows the plot of the vertical displacement of the central orbit $\left(\mathrm{Y}_{\mathrm{cod}}\right)$ when all fourteen kickers fire. The beam displacement is below the median plane of the ring.

\section{Beam Optics of the Extraction Region}

The single beam bunch circulating in the SNS ring is extracted in one turn, upon firing all fourteen extraction kickers. Subsequently the beam bunch is deflected downwards into the main field region of the Lambertson septum magnet which deflected the beam horizontally by $16.8^{\circ}$ into the RTBT beam transfer line.

An optimized beam extraction system requires that the kickers have large enough acceptance to accommodate the $480 \pi[\mathrm{mm} . \mathrm{mrad}]$ emittance of the circulating beam and the $400 \pi[\mathrm{mm} . \mathrm{mrad}]$ of the extracted beam. The beam size at the location of the each kicker is determined from the beam emittance and the $\beta_{x, y}$ functions at the location of the kickers. In addition the vertical aperture of the kicker should allow for the vertical 
displacement of the beam during extraction. The rise time of the voltage of each kicker should be $\sim 90$ nsec therefore the rise time of the Voltage of each kicker which depends on the inductance of the kicker sets an upper limit in the geometrical length of the kicker. The characteristics of each kicker, that depend on the beam optics are tabulated in TableI. A description of the columns that appear in Table I follows:

\begin{tabular}{|c|c|}
\hline Column\# & Description \\
\hline 1 & Name of the Kicker \\
\hline 2 & $\begin{array}{l}\text { Distance of the center of the Kicker from the center of the qudrupole } \\
\text { Q1 (see Fig. 1) The quadrupole Q1 is the first quadrupole of the } \\
\text { straight section. }\end{array}$ \\
\hline 3 & The maximum value of $\beta_{x}$ over the length of the kicker. \\
\hline 4 & The maximum value of $\beta_{y}$ over the length of the kicker. \\
\hline 5 & $\begin{array}{l}\text { The maximum horizontal beam_size of the circulating beam over the } \\
\text { length of the kicker. Horizontal Emittance of the circulating beam } \\
\varepsilon_{\mathrm{x}}=480 \pi[\mathrm{mm} . \mathrm{mrad}] \\
\mathrm{x} \_\operatorname{size}(480 \pi)=2\left(\varepsilon_{\mathrm{x}} \cdot \beta_{\mathrm{x}}\right)^{1 / 2}\end{array}$ \\
\hline 6 & $\begin{array}{l}\text { The maximum vertical beam_size of the circulating beam over the } \\
\text { length of the kicker. Vertical Emittance of the circulating beam } \\
\varepsilon_{\mathrm{y}}=480 \pi[\mathrm{mm} . \mathrm{mrad}] \quad \text { y_size }(480 \pi)=2\left(\varepsilon_{\mathrm{x}} \cdot \beta_{\mathrm{x}}\right)^{1 / 2}\end{array}$ \\
\hline 7 & $\begin{array}{l}\text { The maximum vertical half_beam_size of the extracted beam over the } \\
\text { length of the kicker. Vertical Emittance of the extracted beam }\end{array}$ \\
\hline & $\mathrm{y \_} \operatorname{size}(400 \pi)=2\left(\varepsilon_{\mathrm{x}} \cdot \beta_{\mathrm{x}}\right)^{1 / 2}$ \\
\hline 8 & $\begin{array}{l}\text { The vertical displacement of the central orbit }\left(\mathrm{Y}_{\mathrm{cod}}\right) \text { of the extracted } \\
\text { beam. The value of } \mathrm{Y}_{\text {cod }} \text { is obtained from the output of the } \\
\text { MAD model of the extraction section (See APPENDIX 1) }\end{array}$ \\
\hline 9 & $\begin{array}{l}\text { The vertical aperture of the kicker calculated from: } \\
\text { V_size }=\left\{y \_s i z e(480 \pi)+y \_\operatorname{size}(400 \pi)\right\} / 2+Y_{\text {cod }}\end{array}$ \\
\hline 10 & The Horizontal aperture of the kicker. $\mathrm{H}$ size $=\mathrm{x} \operatorname{size}(480 \pi)$ \\
\hline 11 & $\begin{array}{l}\text { The Maximum vertical aperture of the kicker. It is determined by the } \\
\operatorname{Max}\left\{V_{-} \text {size }(\text { column } \# 9), \text { y_size }(480 \pi)\right\}\end{array}$ \\
\hline 12 & $\begin{array}{l}\text { The Final Horizontal aperture of the spare kickers. } \\
\text { Six sets of spare kickers were selected. The sets of the spare kickers } \\
\text { can satisfy the beam constraints at extraction for all "working points" } \\
\text { selected. The four working points are: }\left(\mathrm{Q}_{\mathrm{x}}, \mathrm{Q}_{\mathrm{y}}\right)=(6.23,6.20) \text {, } \\
(6.23,5.24),(6.30,5.8),(6.40,6.30)\end{array}$ \\
\hline 13 & Same as column 12 but for the Vetrical aperture of the actual kickers \\
\hline 14 & The length of the actual kickers. \\
\hline 15 & $\begin{array}{l}\text { The vertical distance of the inner_top_aperture of the kicker from the } \\
\text { center line of the ring. }\end{array}$ \\
\hline
\end{tabular}

The results tabulated in Table 1 show that the acceptance of the extraction region does not limit either the circulating or extracted beam. 


\section{Parameters of the Kickers}

The extraction kickers, when energized, kick in a one turn, the single beam bunch circulating in the SNS ring, vertically down into the main field region of the septum magnet which deflects the beam by $16.8^{\circ}$ to the left to the RTBT beam_transfer_line. Each extraction kicker has to satisfy the following constraints:

1. The acceptance of the kicker should allow for zero beam losses for both the circulating and extracted beam.

2. The voltage rise time should be $\sim 90$ nsec

3. An upper limit for the kicker voltage is set to $35 \mathrm{kVolts}$.

The content of the columns of Table 2 is explained below.

\begin{tabular}{|c|c|}
\hline Column\# & Description \\
\hline 1 & Name of the kicker \\
\hline 2 & Kick of the kicker \\
\hline 3 & Physical length of the kicker \\
\hline 4 & Horizontal aperture of the kicker \\
\hline 5 & Vertical aperture of the kicker \\
\hline 6 & $\begin{array}{l}\text { The integrated dipole field of the kicker }\left(\int \text { Bydz) given as the }\right. \\
\text { product of the value of the kicker's kick in radians and the } \\
\text { beam rigidity of } 1 \mathrm{GeV} \text { protons. }\end{array}$ \\
\hline 7 & $\begin{array}{l}\text { The approximate strength of the dipole field of the kicker } \\
\text { calculated as: }\left(\int \mathrm{By} \cdot \mathrm{dz}\right) /(\text { Length_of_Kicker })\end{array}$ \\
\hline 8 & $\begin{array}{l}\text { The current of the kickers's coil required to produce the dipole } \\
\text { magnetic field. }\end{array}$ \\
\hline 9 & $\begin{array}{l}\text { The voltage of the kicker required to produce the required } \\
\text { current. }\end{array}$ \\
\hline 10 & $\begin{array}{l}\text { The Inductance of the kicker as calculated from the } \\
\text { geometrical parameters of the kicker. }\end{array}$ \\
\hline
\end{tabular}

\section{Conclusions}

The displacement of each the fourteen beam extraction kickers of the SNS ring, by $5 \mathrm{~cm}$ downstream, can satisfy the same beam extraction condition as the non_displaced kickers by adjusting the voltage of the kickers as follows:

$\begin{array}{lccr}\text { Kicker_Name } & \text { Change[\%] } & \text { Kicker_Name } & \text { Change[\%] } \\ \text { K1 } & +0.3 & \text { K8 } & +1.9 \\ \text { K2 } & +0.6 & \text { K9 } & +1.9 \\ \text { K3 } & +0.6 & \text { K10 } & +1.9 \\ \text { K4 } & +0.6 & \text { K11 } & +1.9 \\ \text { K5 } & +0.6 & \text { K12 } & -3.0 \\ \text { K6 } & +0.3 & \text { K13 } & -3.0 \\ \text { K7 } & +0.3 & \text { K14 } & -3.0\end{array}$




\begin{tabular}{|c|c|c|c|c|c|c|c|c|c|c|c|c|c|c|}
\hline CKER & $\mathrm{S}$ & $\beta_{\mathrm{x}}$ & $\beta_{\mathrm{y}}$ & $\begin{array}{c}\text { Beam } \\
\text { X- } \\
\text { size } \\
\text { for } \\
480 \pi\end{array}$ & $\begin{array}{c}\text { Beam } \\
\text { y- } \\
\text { size } \\
\text { for } \\
480 \pi\end{array}$ & $\begin{array}{c}\text { Beam } \\
\text { y- } \\
\text { size } \\
\text { for } \\
400 \pi\end{array}$ & $\begin{array}{c}\mathrm{y}_{\text {cod }} \\
\text { in } \\
\text { kicker }\end{array}$ & $\begin{array}{c}\text { V- } \\
\text { size } \\
\text { of } \\
\text { kicker }\end{array}$ & $\begin{array}{c}\mathrm{H}- \\
\text { size } \\
\text { of } \\
\text { kicker }\end{array}$ & $\begin{array}{c}\text { Max } \\
\text { V- } \\
\text { size } \\
\text { of } \\
\text { kicker }\end{array}$ & $\begin{array}{c}\text { H- } \\
\text { size } \\
\text { of SP } \\
\text { kicker }\end{array}$ & $\begin{array}{c}\text { V- } \\
\text { size } \\
\text { of SP } \\
\text { kicker }\end{array}$ & Length & $\begin{array}{l}\text { Vertical } \\
\text { Placemen } \\
\text { of Kicker }\end{array}$ \\
\hline & {$[\mathrm{m}]$} & {$[\mathrm{m}]$} & {$[\mathrm{m}]$} & {$[\mathrm{cm}]$} & {$[\mathrm{cm}]$} & {$[\mathrm{cm}]$} & {$[\mathrm{mm}]$} & {$[\mathrm{cm}]$} & {$[\mathrm{cm}]$} & {$[\mathrm{cm}]$} & {$[\mathrm{cm}]$} & {$[\mathrm{cm}]$} & {$[\mathrm{cm}]$} & {$[\mathrm{cm}]$} \\
\hline K1-1 & 2.860 & 7.500 & 9.315 & 12.00 & 13.37 & 12.21 & 0.349 & 12.83 & 12.00 & 13.37 & 12.00 & 13.59 & 40.00 & 6.69 \\
\hline K1-2 & 3.340 & 9.111 & 8.793 & 13.23 & 12.99 & 11.86 & 1.476 & 12.57 & 13.23 & 12.99 & 14.45 & 13.19 & 40.00 & 6.50 \\
\hline K1-3 & 3.820 & 10.934 & 8.337 & 14.49 & 12.65 & 11.55 & 3.296 & 12.43 & 14.49 & 12.65 & 14.45 & 13.19 & 40.00 & 6.33 \\
\hline K1-4 & 4.353 & 13.444 & 7.908 & 16.07 & 12.32 & 11.25 & 6.386 & 12.42 & 16.07 & 12.42 & 17.79 & 12.67 & 50.50 & 16 \\
\hline K1-5 & 4.938 & 16.269 & 7.530 & 17.67 & 12.02 & 10.98 & 10.343 & 12.53 & 17.67 & 12.53 & 17.79 & 12.67 & 50.50 & 1 \\
\hline K1-6 & 5.523 & 19.409 & 7.251 & 19.30 & 11.80 & 10.77 & 15.113 & 12.80 & 19 & 12.80 & 21.13 & 13 & 50.50 & 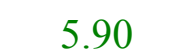 \\
\hline K1-7 & 6.108 & 22.865 & 7.069 & 20.95 & 11.65 & 10.64 & 20.615 & 13.20 & 20.95 & 13.20 & 21.13 & 13.33 & 50.50 & 5.83 \\
\hline K2- & & & 3 & .05 & 9 & 33 & & & & & & & 5 & U \\
\hline $2-2$ & & $12 . \varepsilon$ & 235 & 5.73 & 16.53 & 15.09 & 6 & 2 & & 22.32 & 16.22 & & 5 & \\
\hline K2-3 & & 12.421 & 13.830 & 15.44 & 16.30 & 14.88 & 68.868 & 22.47 & 15.44 & 22.47 & 16.22 & 23.34 & & \\
\hline K2-4 & 10.936 & 12.001 & 13.467 & 15.18 & 16.08 & 14.68 & 73.277 & 22.71 & 15.18 & 22.71 & 16.22 & 23.34 & 42.75 & 8.04 \\
\hline K2-5 & 425 & 11.643 & 13.158 & 14.95 & 15.89 & 14.51 & 77.964 & 23.00 & 14.95 & 23.00 & 15.10 & 24.30 & 39.00 & 7.95 \\
\hline K2-6 & 11.895 & 11.342 & 12.899 & 14.76 & 15.74 & 14.37 & 83.258 & 23.38 & 14.76 & 23.38 & 15.10 & 24.30 & 39.00 & 7.87 \\
\hline K2-7 & 12.365 & 11.083 & 12.675 & 14.59 & 15.60 & 14.24 & 89.158 & 23.84 & 14.59 & 23.84 & 15.10 & 24.30 & 39.00 & 7.80 \\
\hline
\end{tabular}

Table 1: Detailed explanation of the content of this Table is given in the text. 


$\begin{array}{ccccccccccc}\text { KICKER } & \begin{array}{c}\text { Kick } \\ \text { of } \\ \text { kicker }\end{array} & \text { Length } & \begin{array}{c}\text { H-size of } \\ \text { SP kicker }\end{array} & \begin{array}{c}\text { V- } \\ \text { size } \\ \text { of SP } \\ \text { kicker }\end{array} & \text { Bp.kick } & \text { B } & \text { Curr } & \text { Volt } & \text { Induct } \\ & \text { [mrad] } & {[\mathrm{cm}]} & {[\mathrm{cm}]} & \begin{array}{c} \\ {[\mathrm{cm}]}\end{array} & {[\mathrm{G} . \mathrm{m}]} & {[\mathrm{Gauss}]} & {[\mathrm{kA}]} & {[\mathrm{kV}]} & {[\mu \mathrm{H}]} \\ \text { K1-1 } & 1.745 & 40.00 & 12.00 & 13.59 & 98.72 & 246.81 & 2.36 & 33.7 & 56.926 \\ \text { K1-2 } & 1.445 & 40.00 & 14.45 & 13.19 & 81.75 & 204.38 & 2.35 & 33.6 & 45.882 \\ \text { K1-3 } & 1.445 & 40.00 & 14.45 & 13.19 & 81.75 & 204.38 & 2.35 & 33.6 & 45.882 \\ \text { K1-4 } & 1.490 & 50.50 & 17.79 & 12.67 & 84.30 & 166.92 & 2.36 & 33.8 & 45.196 \\ \text { K1-5 } & 1.490 & 50.50 & 17.79 & 12.67 & 84.30 & 166.92 & 2.36 & 33.8 & 45.196 \\ \text { K1-6 } & 1.250 & 50.50 & 21.13 & 13.33 & 70.72 & 140.04 & 2.35 & 33.6 & 40.034 \\ \text { K1-7 } & 1.250 & 50.50 & 21.13 & 13.33 & 70.72 & 140.04 & 2.35 & 33.6 & 40.034 \\ & & & & & & & & & \\ \text { K2-1 } & 1.295 & 42.75 & 16.22 & 23.34 & 73.26 & 171.38 & 2.21 & 31.6 & 77.303 \\ \text { K2-2 } & 1.295 & 42.75 & 16.22 & 23.34 & 73.26 & 171.38 & 2.21 & 31.6 & 77.303 \\ \text { K2-3 } & 1.295 & 42.75 & 16.22 & 23.34 & 73.26 & 171.38 & 2.21 & 31.6 & 77.303 \\ \text { K2-4 } & 1.295 & 42.75 & 16.22 & 23.34 & 73.26 & 171.38 & 2.21 & 31.6 & 77.303 \\ \text { K2-5 } & 1.290 & 39.00 & 15.10 & 24.30 & 72.98 & 187.13 & 2.25 & 32.1 & 78.868 \\ \text { K2-6 } & 1.290 & 39.00 & 15.10 & 24.30 & 72.98 & 187.13 & 2.25 & 32.1 & 78.868 \\ \text { K2-7 } & 1.290 & 39.00 & 15.10 & 24.30 & 72.98 & 187.13 & 2.25 & 32.1 & 78.868\end{array}$

Table 2: Parameters of the extraction kickers. For detailed explanation please refer to the text.

\section{References}

[1] Beam Extraction from the SNS Ring and Design of Extraction Kickers N. Tsoupas, M. Blaskiewicz, Y. Y. Lee, J. L. Mi, A. Soukas, J. G. Wang, J. Wei, and, S. Y. Zhang BNL, EPAC2000, p. 2270, Vienna, Austria 2000

[2] Design of Beam-Extraction Septum Magnet for the SNS

N. Tsoupas, Y.Y. Lee, J. Rank, J.E.Tuozzolo BNL

PAC2001,Chicago,Illinois,June18-22, 2001

[3] Beam Coupling Phenomena in Fast Kicker Systems W. Zhang, L.A. Ahrens, J.W. Glenn, J. Sandberg, N. Tsoupas, BNL PAC2001,Chicago,Illinois,June18-22, 2001

[4] A New Conceptural Design of the SNS Full Turn Fast Extraction Kicker Power Supply System. W. Zhang, R. Lambiase, J.L. Mi, T. Nehring, C. Pai, J. Sandberg, N. Tsoupas, J.E. Tuozzolo, D. Warburton BNL, PAC2001,Chicago,Illinois,June18-22, 2001 
[5] SNS Extraction Kicker System and First Article BPFN Test J.-L. Mi, D. Davino, H. Hahn, R.F. Lambiase, Y.-Y. Lee, W. Meng, C.-I. Pai, J. Sandberg, N. Tsoupas, D. Warburton, W. Zhang, BNL, Upton, Long Island, New York EPAC 2002 Paris, France, June 2, 2002

[6] SNS Extraction-Fast-Kicker System Development.

W. Zhang, et. al., $14^{\text {th }}$ IEEE International Pulsed Power Conference, Dallas, TX, June $15-19,2003$

[7] SNS Extraction Fast Kicker Pulsed Power System W. Zhang et al. EPAC 2004 Lucerne, Switzerland July 5-9 2004

.[8] SNS Extraction Kicker Power Supply Manufacture Status J.-L. Mi, et. al. EPAC 2004 Lucerne, Switzerland July 5-9 2004

[9] Preliminary Study of the Magnetic Field of the SNS Lambertson-type Extraction Septum Magnet

N. Tsoupas, J. Browdoski, Y.Y.Lee, J. Tuozzolo BNL SNS-54 12/22/98

[10] Design of Beam-Extraction Septum Magnet for the SNS N. Tsoupas, Y.Y. Lee, J. Rank, J.E.Tuozzolo BNL

PAC2001,Chicago,Illinois,June18-22, 2001

\section{APPENDIX}

This appendix contains the MAD_input file which was used to optimize the beam optics of the extraction region of the SNS ring. This file corresponds to the working point $\left(\mathrm{Q}_{\mathrm{x}}, \mathrm{Q}_{\mathrm{y}}\right)(6.23,6.20)$.

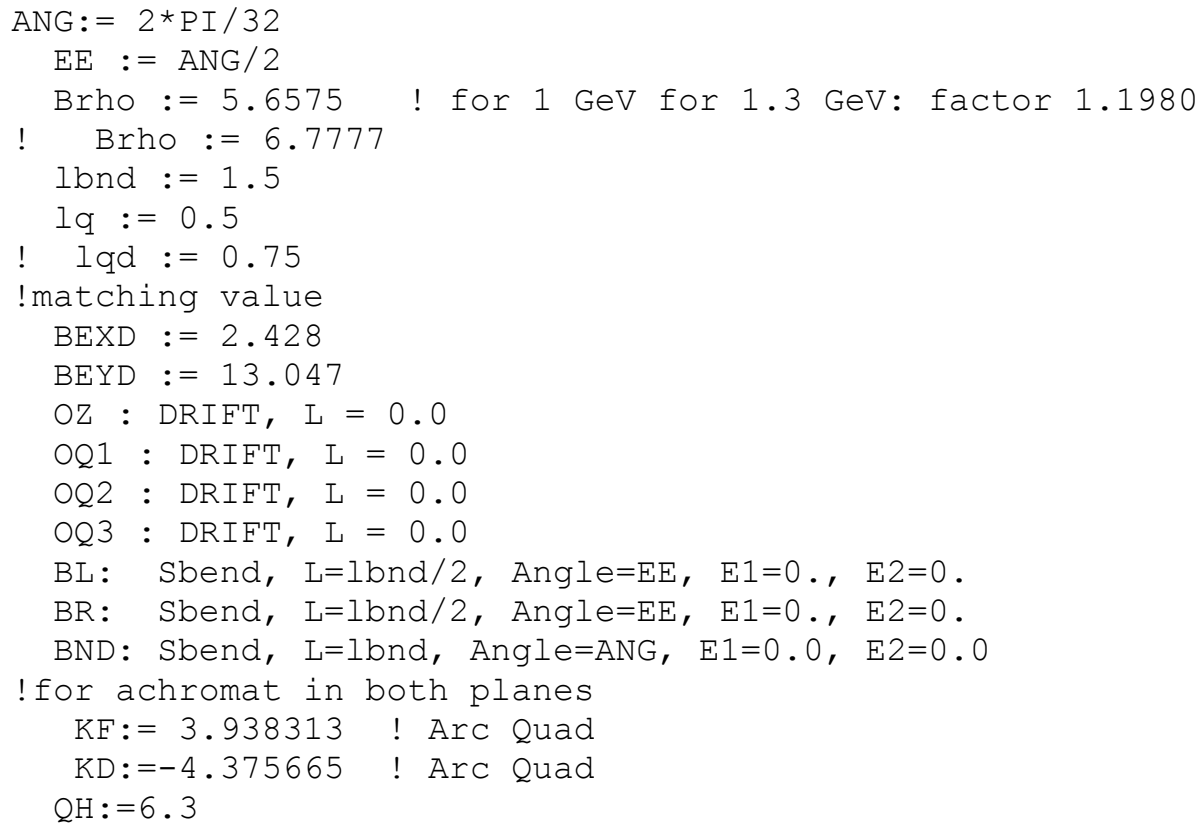




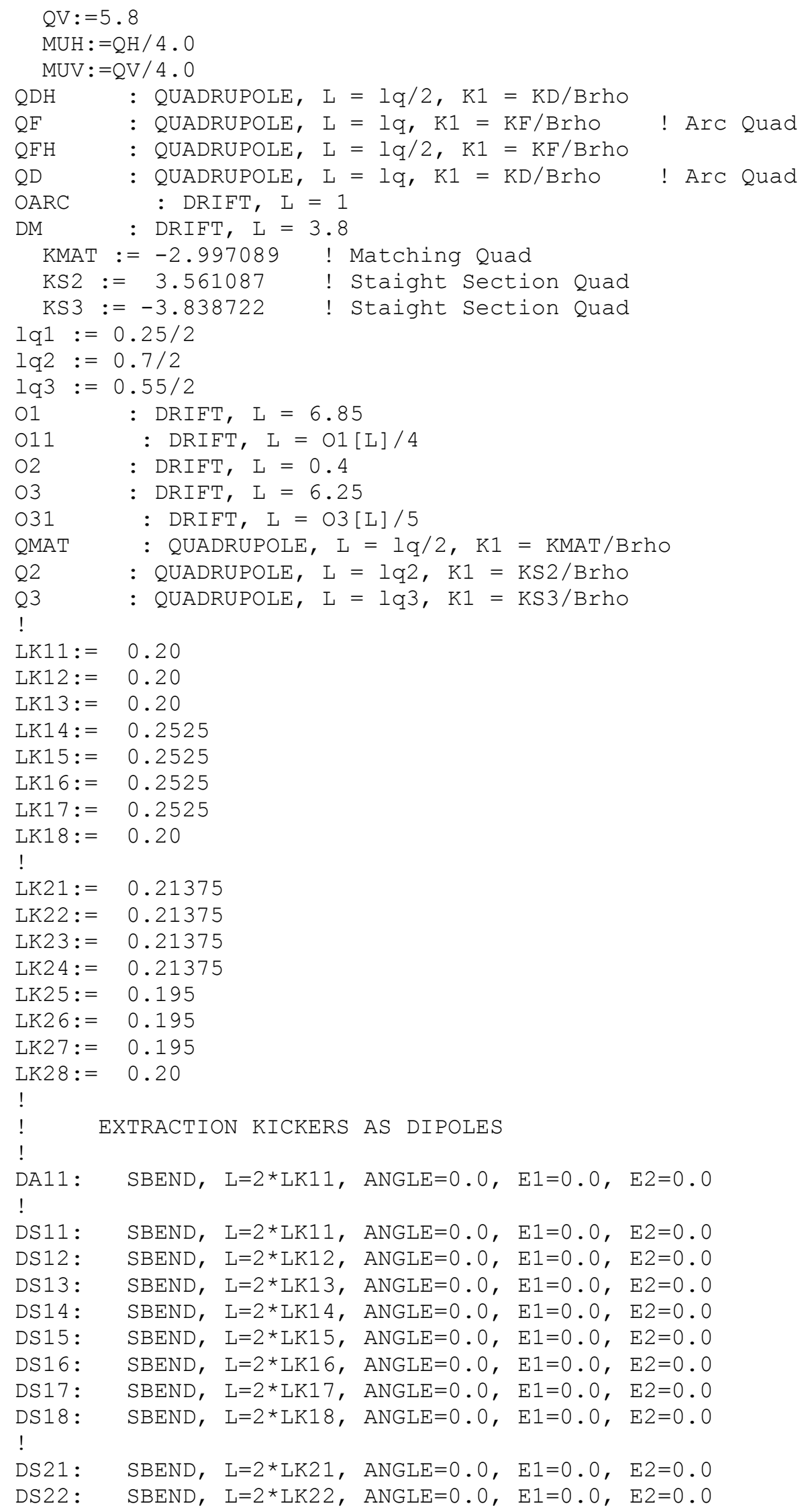




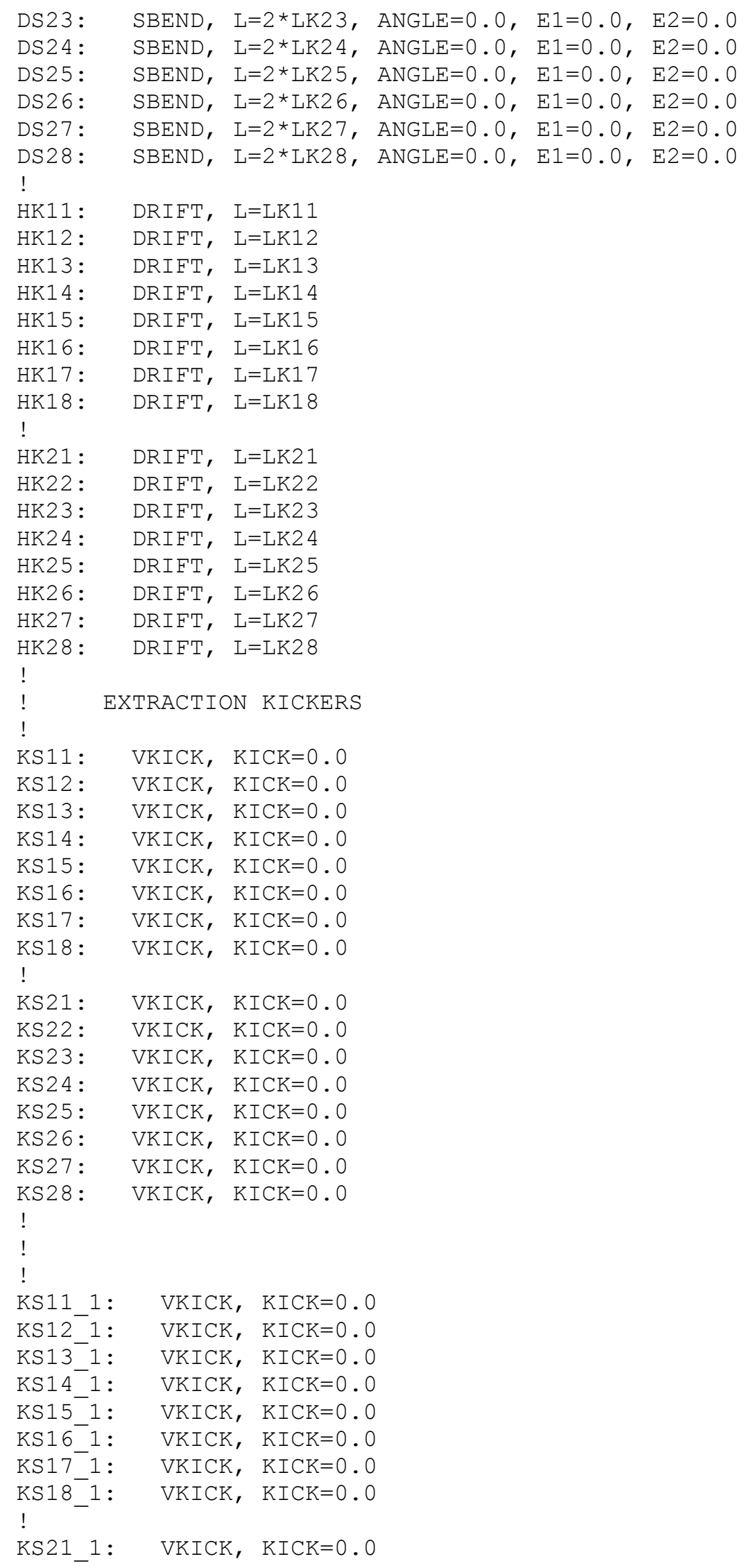




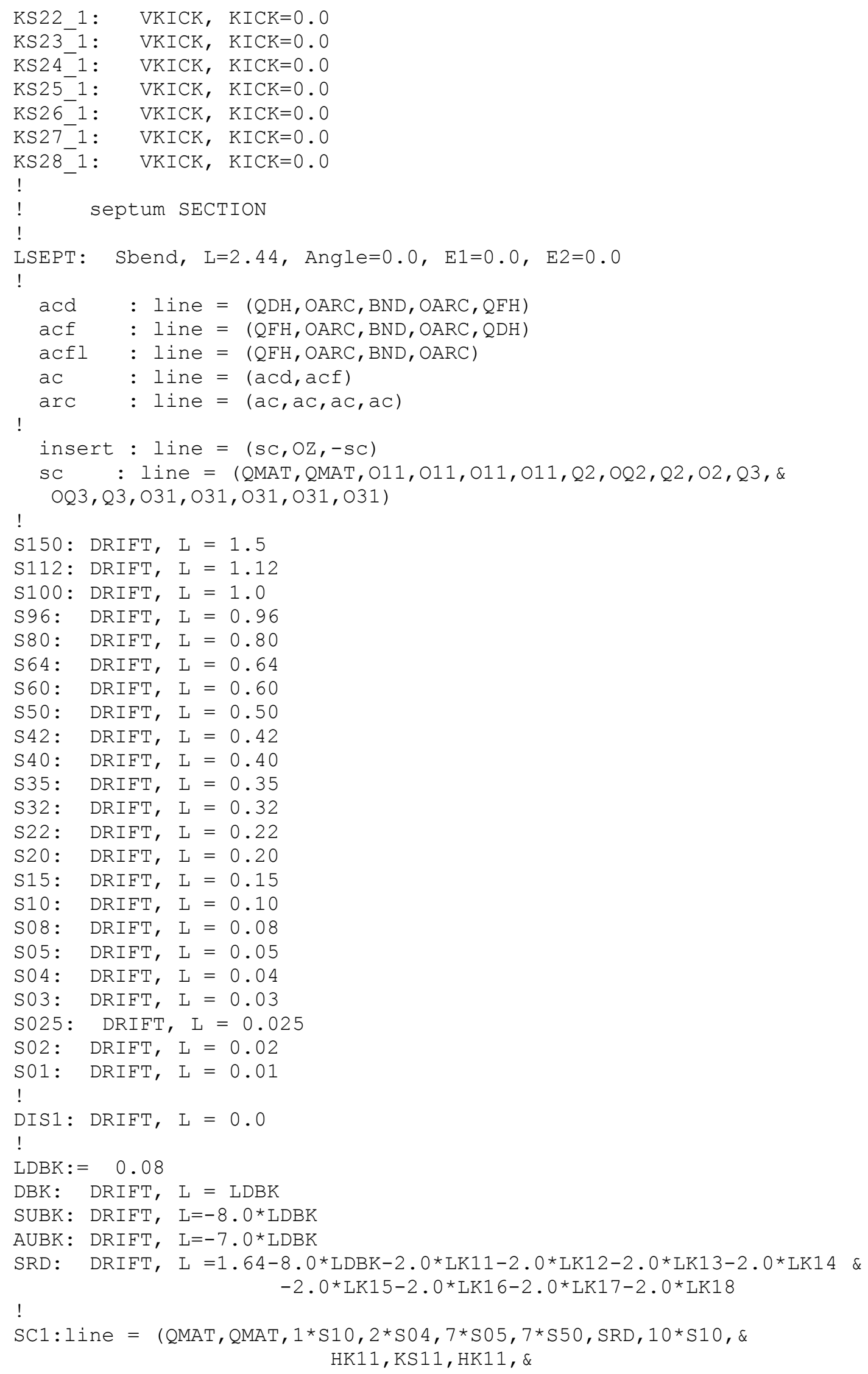




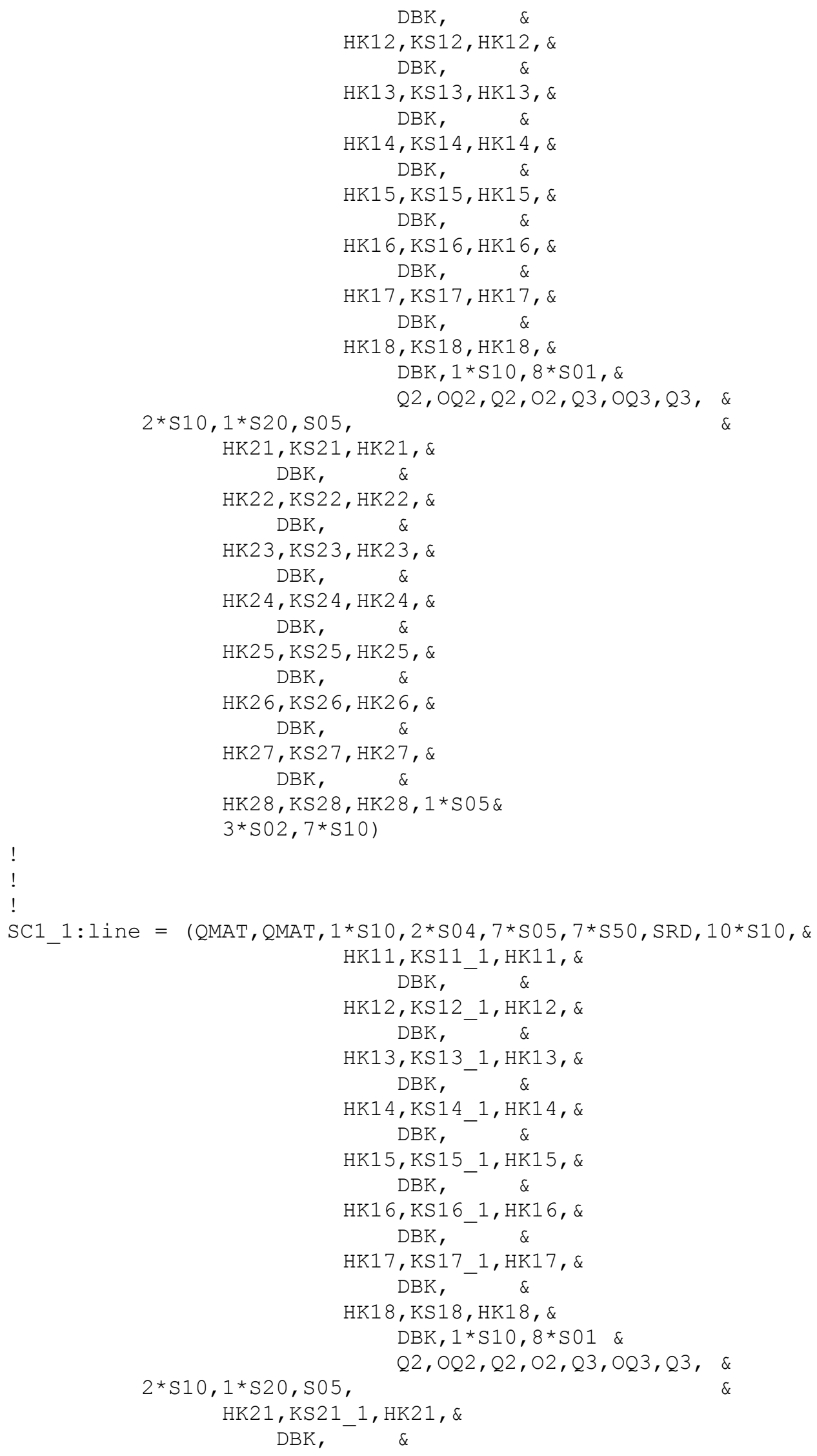




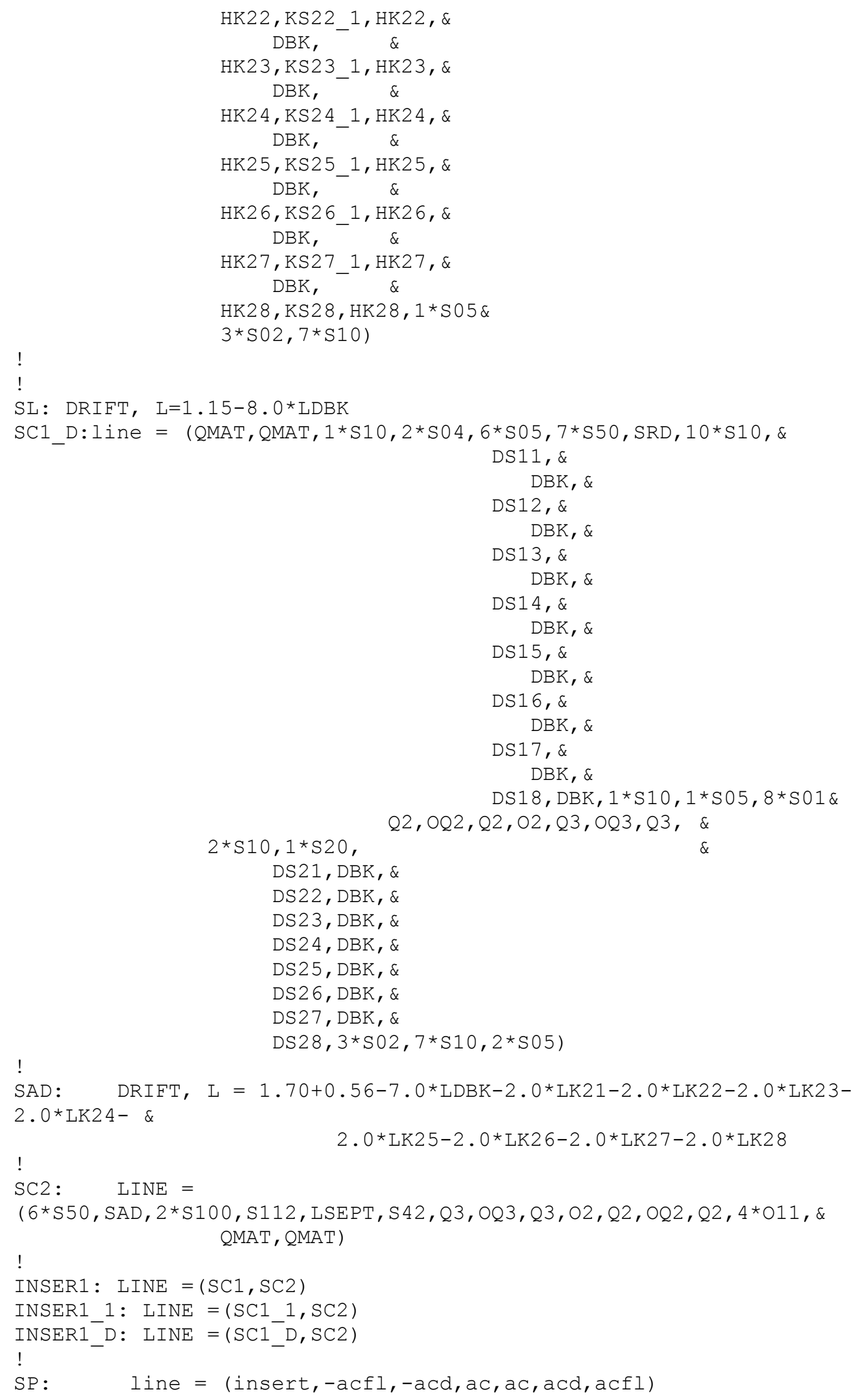




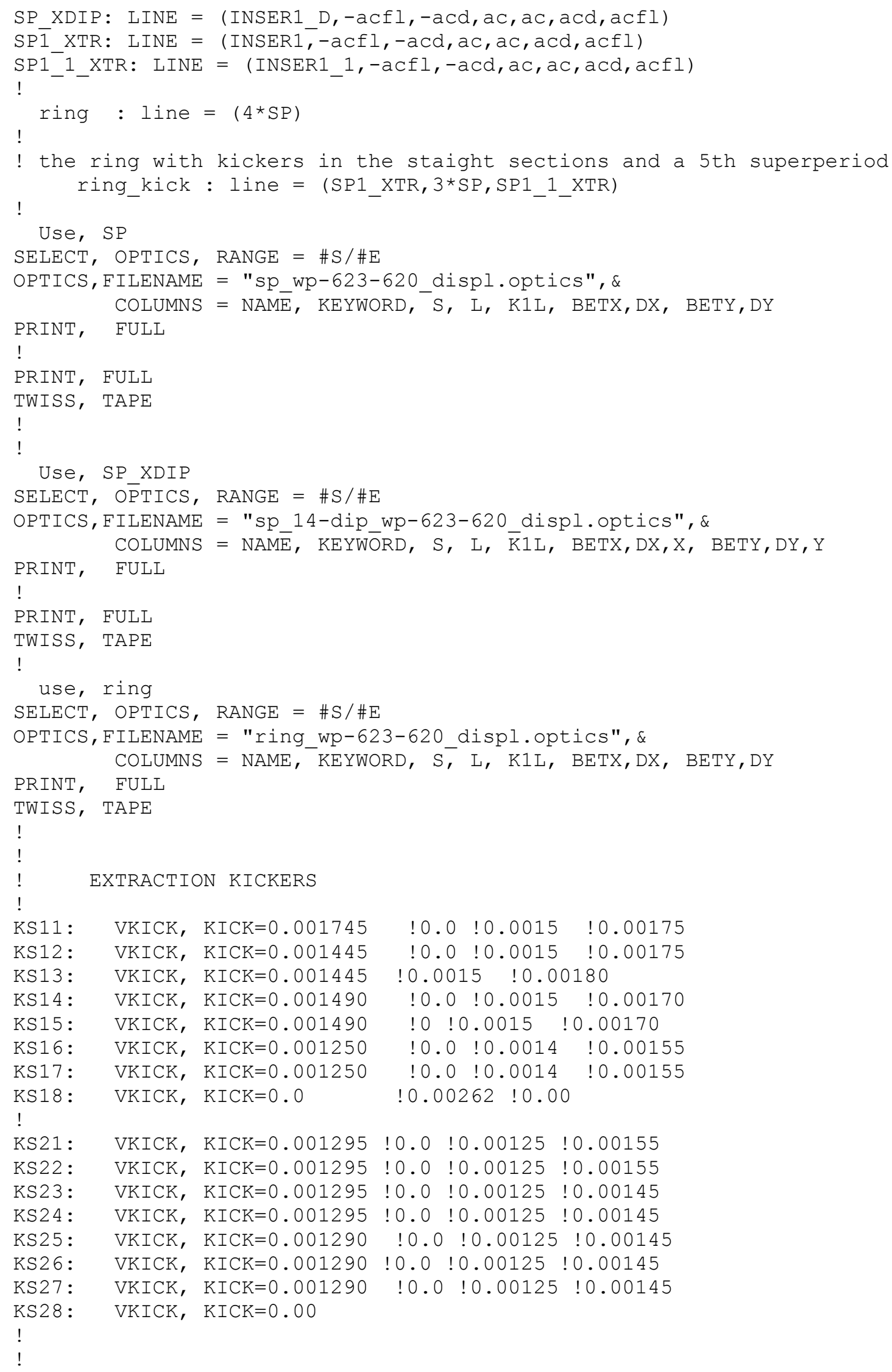




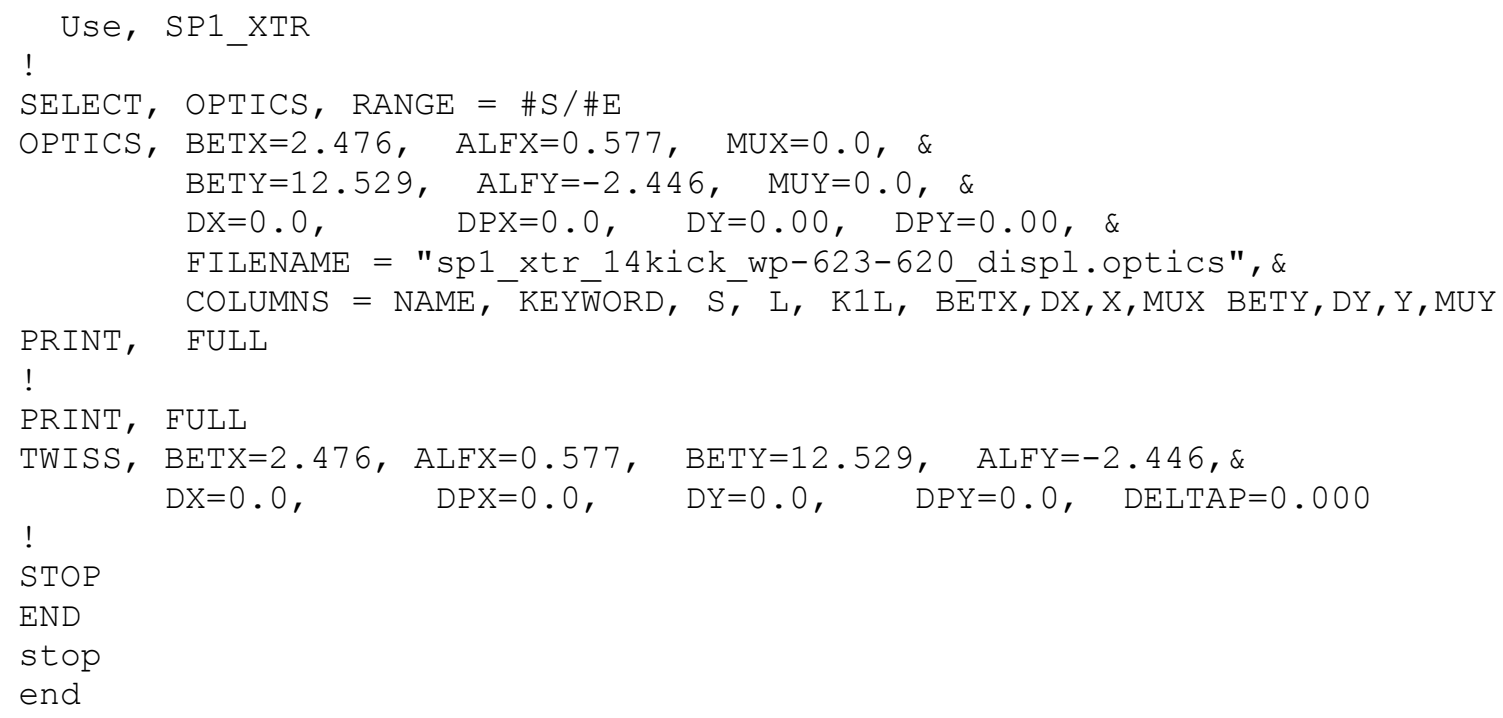

